\title{
Bases teóricas do projeto Geo-Escola: uso de computador para ensino de Geociências
}

\author{
Celso Dal Ré Carneiro ${ }^{1}$, Ronaldo Barbosa ${ }^{2}$ \& Joseli Maria Piranha ${ }^{3}$
}

\begin{abstract}
Resumo O projeto Geo-Escola disponibiliza material didático em CD-ROM a professores de educação básica de uma dada região, contendo informações geológicas, imagens e mapas. O projeto desenvolve-se em módulos-pilotos regionais: dois foram concluídos nas regiões paulistas de Jundiaí-Atibaia e São José do Rio Preto, e um está em andamento, em Campinas. A pesquisa inicia-se por uma consulta a docentes de Ciências e Geografia, dos níveis de ensino fundamental e médio, sobre temas de Geociências que mais os interessam. Priorizados os temas pelos docentes, estabelece-se interação que pode envolver aulas teórico-práticas e trabalhos de campo. Nos módulos concluídos os professores mostraram-se desejosos de aprimorar sua qualificação sobre dinâmica terrestre, ciclos da água e das rochas, com destaque para o reconhecimento de que o ensino de Geologia / Geociências deva exercer papel mais ativo para formar uma cultura de sustentabilidade, na medida em que inclui a compreensão de como funciona o planeta, sua história e de que modo, no tempo e no espaço, as relações da vida se estabelecem. Para educar um cidadão sensível e responsável, a educação básica deveria permitir que o indivíduo reconhecesse aspectos fundamentais da própria região onde vive. No contexto da moderna Ciência do Sistema Terra e, em especial, da Geologia, o uso didático do computador pode explorar sobretudo a linguagem visual, fortemente vinculada ao raciocínio geológico, mas requer incentivos em capacitação do professor. O computador pode ainda estimular o debate, a interpretação e a imaginação, valorizando procedimentos metodológicos típicos da Geologia, como múltiplas hipóteses explicativas, visualidade, raciocínios histórico e analógico. Muitos especialistas da comunidade nacional de Geologia estão bem capacitados a decodificar conceitos centrais a partir da grande massa de informações disponíveis. Ao se promover interação junto a professores, abrem-se promissoras oportunidades de difusão das Geociências.
\end{abstract}

Palavras-chave: Educação, ensino, Geociências, computadores, educação básica.

Abstract Theoretical foundations of the Geo-School Project: the use of computers for geosciences teaching. The Geo-School project offers digital didactic materials to teachers of basic education of a given region. The material in CD-ROM comprises geologic data, images and maps. Three pilot-modules were developed at the basic- and medium-levels of education (the Brazilian basic education) in the São Paulo State: Jundiaí-Atibaia, São José do Rio Preto and Campinas. The research has been started from an inquiry to teachers of Sciences and Geography of public and private educational institutions about themes that should be emphazised in classroom. After the themes are prioritized the resulting interaction involves lectures, theoretical-practical courses and fieldwork. The enrolled teachers have demanded a broader professional qualifying because they have been challenged to approach some interdisciplinary concepts as the terrestrial dynamics, water cycle and rock cycle. The project also reveals that teaching of geology / geosciences should play an active role to help forming a culture of sustainability. Education should allow any individual to recognize what the planet is, how it functions and the way life relationships develop, both in time and space. In a broad sense, Geosciences (as the modern conception of Earth System Science) may help students to construct an idea on mechanisms of planetary evolution and on the permanent interaction between the Earth spheres. The use of computers in education may explore visual language, which is strongly connected to geologic reasoning, as well as some typical methodological procedures of Geology, as multiple explanatory hypotheses, scientific descriptions, historical and analogical reasoning. This requires more incentive towards teacher training programs. Many specialists of the national community of Geology are the most capable people to decode principal concepts from a great volume of available information. Promoting interaction with teachers seems to open promising opportunities for diffusion of Geosciences.

Keywords: Education, teaching, Geosciences, computers, basic education.

INTRODUÇÃO Na condição de campos do conhecimento ligados aos estudos da natureza, as Ciências da Terra oferecem enorme potencial para aprimorar a educação básica, uma vez que despertam nos alunos

1 - DGAE, Instituto de Geociências Unicamp, Campinas, SP, Brasil. E-mail: cedrec@ige.unicamp.br

2 - Doutorando no DGAE, Instituto de Geociências Unicamp. Campinas, SP, Brasil. E-mail: ronaldob@ige.unicamp.br

3 - DQCA, Instituto de Biociências, Letras e Ciências Exatas UNESP. São José do Rio Preto, SP. Brasil. E-mail: joseli@ibilce.unesp.br 
importantes reflexões sobre as relações do homem com o planeta. O ensino de Ciências e Geografia pode ser beneficiado pela observação dos processos naturais e seus produtos, da qual resultou a moderna visão holística e interdisciplinar de Sistema Terra, na qual as diferentes esferas materiais interagem entre si e com a esfera representada pela noosfera (esfera social) ou antroposfera (a esfera humana). A abordagem relaciona os fenômenos naturais às intervenções humanas, identificando agentes e/ou etapas dos ciclos da água e das rochas. São exemplos correntes: enchentes, erosão acelerada, secas prolongadas, perda de solos agrícolas, desertificação, efeito estufa, camada de ozônio, furacões, tornados, vulcões e terremotos.

A escola básica, no Brasil, compreende o nível de ensino fundamental (que recentemente passou a ter nove anos de duração, sendo oferecido a jovens de 6 até de 14 anos de idade) e médio (três anos de duração, para pessoas de 15 a 18 anos). Temas de Geologia, quando adequadamente inseridos nesses níveis escolares, podem permitir abordagens de aspectos locais das regiões onde os alunos vivem, estimular indagações ou simplesmente despertar curiosidade. É importante avaliar em que medida esse interesse pode ser conciliado com o grande estímulo educacional representado pelo computador, em diferentes contextos e níveis escolares. A Informática como ferramenta pedagógica passou a exigir dos educadores ampla reflexão sobre valores e posturas adotados (Carmo 2004). Além de facilitar a preparação de aulas, diariamente surgem novas possibilidades de atualização docente, por meio da internet; ampliam-se a criatividade e a comunicação entre alunos e professores. O papel do professor vem sendo repensado, pois o acesso amplo a informações estimula questionamentos e discussões, que aumentam o interesse dos alunos pelas atividades, mas exigem aprofundamento conceitual.

Carneiro e Barbosa (2002, 2005), Barbosa (2003) e Piranha (2006) sintetizaram resultados de pesquisas sobre formas de uso de recursos computacionais que pudessem contribuir para resgatar ou aprimorar o ensino de Geociências na escola básica brasileira. A investigação possibilitou desenvolver o Projeto Geo-Escola, cujo ponto de partida é a idéia de que os conteúdos de Geociências são capazes de oferecer rica contribuição à formação dos alunos da escola básica, embora estejam pobremente representados nesses níveis escolares.

O presente artigo discute os fundamentos teóricos do Projeto Geo-Escola, reconhecendo que a aplicação de computadores no ensino de determinada disciplina requer entendimento da natureza do campo de conhecimento envolvido.

PROJETO GEO-ESCOLA Paschoale et al. (1981) apresentam conjunto de argumentos para incentivar o desenvolvimento de cultura geológica em escolas. Carneiro et al. (2004c) estendem a lista e defendem maior inserção escolar de conteúdos de Geologia e Geociências nas diversas etapas da educação básica, apoiados em exemplos extraídos das diretrizes educacionais em vigor (Brasil/PCN 1999). Concluem que as Geociências possibilitam "trazer o mundo real para a sala-de-aula"; ao mesmo tempo, sua inserção na educação básica permite realizar a ação recíproca, "levar a sala-de-aula para o mundo real".

Amaral (1991) aponta vínculos no $1^{\circ}$ Grau (nome dado à escola fundamental) entre o ensino de Ciências, a educação ambiental e o ambiente, sugerindo que os currículos se integrassem em proposta educacional na qual o ambiente terrestre geraria incontáveis temas para ensino-aprendizagem e estabeleceria vínculos progressivos entre diferentes aspectos da realidade conhecida, percebida ou vivenciada pelo aluno.

Barbosa (2003) considera que, do ponto de vista das Geociências: (1) os conhecimentos de Geociências veiculados na educação básica, no Brasil, limitam-se a inserções isoladas em disciplinas como Geografia e Ciências; (2) inexiste disciplina específica de Geociências (ou Geologia) para abordar tais conteúdos, desde que, nos anos 1960, História Natural deu lugar a Biologia.

A educação básica deve abordar traços gerais de várias questões contemporâneas relacionadas ao ambiente. As Ciências Geológicas estimulam reflexão sobre relações do homem com o planeta, favorecem a adoção de novas atitudes e valores e ajudam o aluno a avaliar ações de "interferência, ocupação e uso do ambiente" (Brasil/PCN 1999). Apesar do incentivo oficial à abordagem da realidade natural, na prática houve abandono de temas geocientíficos. A fragmentação do conhecimento da Terra existente no ensino brasileiro deve-se ao fato de que conceitos de Geociências dispersam-se em várias disciplinas (Carneiro et al. 2004a, 2004b) subordinados a abordagens específicas (Toledo comunicação oral). Dispersas nos currículos, as noções de Geologia e Geociências são incapazes de explicar a Terra, sua constituição, origem e evolução, os fenômenos e as interações entre oceanos, atmosfera, continentes, o ambiente físico e os seres vivos.

Em termos ideais, qualquer conteúdo desenvolvido no ensino pode ser abordado por meio do computador, em quaisquer disciplinas. Barbosa (2003) avalia que o uso do computador pode abrir novas oportunidades educacionais, mas não se conhece o grau de uso do computador como auxiliar na produção de material didático pelos professores. Para esse autor, parece predominar no ensino a aula expositiva, ilustrada por materiais eventualmente selecionados pelo professor, sendo necessário pesquisar outros papéis que estes recursos possam desempenhar. $\mathrm{O}$ uso de tecnologias computacionais na mediação pedagógica permite contato dos alunos com informações recentes, pesquisas e produções científicas do mundo todo, além de estimular "a auto-aprendizagem e a interaprendizagem à distância (...) possibilitando a orientação do aluno (...) não apenas nos momentos de aula, mas nos períodos entre aulas também" (Massetto 2003). Ademais, a informática na educação desenvolve capacidade crítica para avaliar o que se recebe por meio do computador, curiosidade 
e interesse pela novidade, criatividade para melhorar a capacidade de expressão, e fortalece uma postura ética baseada em valores contemporâneos.

Objetivo do Projeto Geo-Escola O Projeto Geo-Escola nasceu de duas hipóteses básicas de trabalho (Carneiro e Barbosa 2002, 2005): (1) a difusão de informações sobre a Geologia de uma determinada região tem interesse direto para os docentes que nela exercem seu trabalho; (2) é pouco provável que exista no Brasil uma região sobre a qual se tenha produzido e compartilhado material didático em Geociências para uso na educação básica local.

O objetivo do Projeto Geo-Escola consiste em “disponibilizar dados geológicos, imagens e mapas, de uma dada região, em formato de material didático com suporte em computador, a professores de ensino fundamental e médio" (Carneiro e Barbosa 2005).

Métodos de Trabalho Para viabilizar o alcance do objetivo geral, o método de trabalho desdobrou-se em frentes complementares: inicialmente analisam-se especificidades dos conteúdos de Geociências a serem transmitidos a estudantes e professores convidados. Em seguida, avalia-se, sob o ponto de vista do professor, qual o interesse e qual sua disposição para realizar mudanças que aumentem a inserção desses conteúdos. Finalmente, é preciso delimitar o assunto da pesquisa em relação a uma área geográfica, e fixando-se um certo nível de ensino, para que os temas não fiquem amplos demais ou restritos demais.

$\mathrm{Na}$ primeira versão do projeto, planejava-se transformar temas abordados em determinada disciplina introdutória de Geociências em softwares educativos do tipo tutorial. Entretanto, a dinâmica das aulas se revelou, em muitos momentos, praticamente intraduzível para o ambiente do computador. Na primeira aula os alunos discutiram em grupo o significado e as relações entre duas imagens reproduzidas em papel, que representavam fotos feitas de um mesmo local em épocas diferentes, separadas no tempo por intervalo de cinco anos (Fig. 1); indagava-se qual das fotos teria sido obtida primeiro: a duna teria avançado ou recuado sobre a estrada? Ou teria sido a estrada desviada para contornar a duna? Para responder, as imagens deveriam ser observadas cuidadosamente, e hipóteses deveriam ser formuladas e discutidas, ao longo de toda uma aula. Percebeu-se, nesse caso, que nenhum benefício decorreria da utilização de computadores em apoio àquela atividade.

O exemplo da série temporal de dunas fortaleceu a idéia de que o uso de imagens no ensino seria benéfico, sobretudo por estimular a curiosidade dos participantes. A existência de mapas e relatórios resultantes de uma pesquisa mais ampla, que focalizou área entre os municípios de Jundiaí e Atibaia, facilitou a coleta de imagens de problemas ambientais de uma região situada próxima à Região Metropolitana de São Paulo. Os dados serviriam de base para desenvolvimento de exercícios práticos e questões sobre a região. Buscou- se avaliar em paralelo a demanda de informações e conhecimentos especializados de Geociências e a disponibilidade de salas-ambiente para ensino baseado no computador.

O método geral de desenvolvimento envolve: (a) avaliação das fontes de informação disponíveis; (b) questionário de consulta para instituições de ensino da área abrangida pelo módulo, (c) definição de temas prioritários, selecionados pelos professores; (d) desenvolvimento de material didático em CD-ROM; (e) aplicação; (f) avaliação do material fornecido e das alternativas de mudança didática implementadas. A etapa final exige interlocução com professores na tentativa de diagnosticar novos encaminhamentos.

FUNDAMENTAÇÃO TEÓRICA Atualmente, o tratamento das informações geradas pelos complexos aparatos tecnológicos de observação e monitoramento da Terra requer utilização de conceitos ligados às Geociências, essenciais para que se compreendam as linhas mestras de funcionamento da dinâmica do planeta e do meio natural.

Computadores e ensino O principal motivo para integrar informática e educação é porque computadores estão cada vez mais presentes na vida cotidiana de todos nós e fazem parte do universo dos jovens (Belloni 1999).

\footnotetext{
“Os professores ou os teóricos da educação que só parecem estar dispostos a utilizar e considerar tecnologias que conhecem, dominam e com as que se sentem minimamente seguros, por considerá-las não perniciosas, não prestando atenção às produzidas e utilizadas na contemporaneidade, estão, no mínimo, dificultando aos seus alunos a compreensão da cultura do seu tempo e o desenvolvimento do juízo crítico sobre elas" (Sancho 1998).
}

Há séculos a humanidade e a escola lidam com informações em suportes analógicos: livros, lousa, cadernos... Há poucas décadas a representação da informação começou a migrar do formato analógico para o digital; a tecnologia mudou também a forma como esta é transmitida e o processo de mudança se acelerou. O simples armazenamento da informação em suporte digital não garante mudanças significativas de função, mas a facilidade com que pode ser transformada é um convite ao reaproveitamento, reedição e busca de novas abordagens (Levy 1999).

Na passagem do analógico para o digital estaria a encruzilhada do uso de computadores na escola: se os livros ou a lousa simplesmente derem lugar a grandes telas de computador ligadas à internet, mantendo-se as mesmas rotinas tradicionais de ensino, haveria apenas troca de suportes e a escola tradicional se manteria como sempre foi. Por outro lado, se for aproveitado no ensino o convite a novas abordagens, pode haver uma reviravolta nos papéis tradicionais do aluno como receptor da informação e do professor como transmissor 

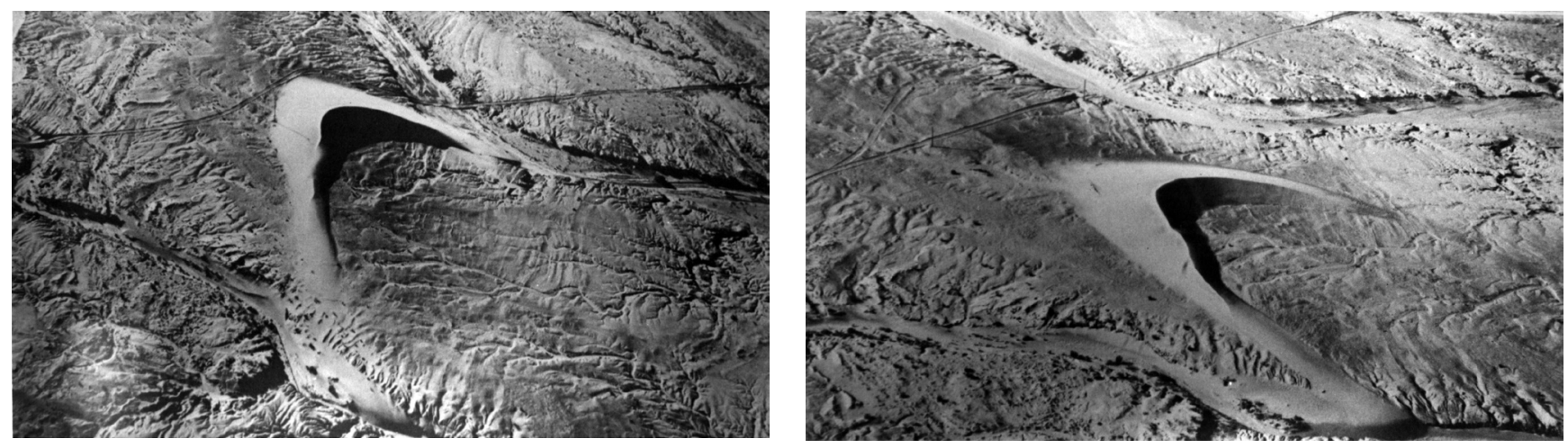

Figura 1 - Par de fotografias utilizadas durante aula prática sobre interpretações cientificas, evidências e provas. (Fonte: ESCP 1973)

desta. O computador no ensino-aprendizagem desperta reflexões sobre prática educacional, a exemplo de outros instrumentos de apoio didático como cartazes, vídeos, slides e transparências. Nenhum deles é mais versátil e poderoso que o computador: além de suportar praticamente todas as modalidades audiovisuais de apoio ao ensino, ajusta-se melhor, também, como recurso, ao estilo cognitivo do aluno.

\begin{abstract}
"A educação com multimeios tem algumas vantagens suplementares. Cada meio ativa nos alunos alguns mecanismos perceptivos e mentais diferentes. A educação com multimeios permite, então, adaptar-se às capacidades perceptivas e mentais dos diversos alunos, compensando os déficits derivados da aprendizagem com outros meios expressivos" Ferrés (1998, p.136).
\end{abstract}

O uso do computador pode construir ambientes de estudo estimulantes, adaptáveis a diferentes situações, e de certo modo experimentais.

Anguita (2005) vê motivo de preocupação com o uso indiscriminado de programas de apresentação em aulas. Refere-se ao MS-Powerpoint como um "atropelo tecnológico disfarçado de modernidade". O recurso corre perigo de tornar as aulas expositivas ricamente ilustradas, mas incapazes de despertar o raciocínio crítico, explorar o contraditório, e, em síntese, estimular a capacidade criativa dos estudantes.

Os atos de ensinar e aprender são formas de conversar (Wagensberg 2002, apud Anguita 2005). Apresentações enfadonhas correm o risco de eliminar completamente a conversação nas aulas. Há exemplos de uso adequado, mas certos parâmetros devem ser respeitados: (1) o uso de imagens bem selecionadas: imagens devem ser incluídas não pelo fato de estarem à mão, mas porque constituem veículos necessários para a compreensão; (2) o uso de textos concisos, em lugar de quantidades abusivas de informação, tendência nefasta oriunda dos tempos do retroprojetor (Anguita 2005). Aulas constituem oportunidade que não pode ser desperdiçada, mas as aulas desestimulantes dependem de "intervenção decidida e pessoal do professor", o único que pode efetivamente entusiasmar os alunos.
Considerando que os computadores constituem realidade inevitável - na produção de conhecimento científico novo e no ensino - cabe rever brevemente as abordagens de ensino de ciências, tendo em vista que diferentes formas de utilização de computadores poderiam decorrer dessas abordagens.

ABORDAGENS As novas tecnologias de informação e comunicação (TIC) poderiam favorecer novas abordagens educacionais uma vez que geram oportunidades para que o aluno sintetize, organize e reestruture a informação, além de permitir que o próprio aluno controle o tempo, espaço e velocidade da aprendizagem; o acesso a informações independe da localização geográfica; a melhor comunicação entre alunos facilita o aprendizado cooperativo; as fontes de informação se deslocam do professor e do livro-texto para uma fonte variadíssima e dinâmica de informações da qual o próprio aluno pode ser provedor (Globe 2003). A Internet e as TIC ofereceriam o caminho para renovar ou até revolucionar o ensino. Contudo, pode-se argumentar que uma parte das inovações supracitadas é conhecida desde o ensino programado e as "máquinas de ensinar" a serviço das teorias psicológicas comportamentais da década de 1950 (Oppenheimer 1997).

Tal constatação contribui para enfraquecer a percepção apressada do poder de mudanças associado ao uso do computador no ensino, se tomado de forma isolada, sem referências a um contexto maior, e independente de o uso do computador estar (ou não) associado a pretensões mais ou menos inovadoras.

De modo simplificado, a pedagogia viveu do final do século XIX até perto do final do século XX três fases distintas (Saviani 2000): a pedagogia tradicional identificada com o "aprender", que deu lugar à pedagogia nova, identificada com o "aprender a aprender" e, finalmente, a pedagogia tecnicista onde "aprender é atingir". Assim, a questão pedagógica deslocou seu eixo temático do conteúdo e da lógica (restrição ao ato de "aprender") para o sentimento e a psicologia (aprendizado "para se aprender"), mais tarde para a busca da eficiência, operacionalidade e objetividade ("atingir"). Enquanto na pedagogia tradicional cabia ao professor o elemento decisivo e papel de sujeito do processo, na 
pedagogia que veio a seguir, o cerne da relação educativa passou a ser a relação professor-aluno e a relação interpessoal (Saviani 2000).

TECNICISMO Na pedagogia tecnicista os meios definem o que professores e alunos devem fazer, como e quando farão; o processo educativo submete-se ao planejamento e à tecnologia. As teorias comportamentais apoiadas no ensino programado e as máquinas de ensinar ainda exercem grande influência e estão presentes em numerosos aspectos do ensino "tecnicista" atualmente sob novas roupagens.

\begin{abstract}
“(...) no ensino tecnicista, a inovação educacional ocorrerá com a alteração dos métodos, das formas de educar, sendo entendida apenas em função do aparelho educacional, sem referência ao contexto. As dificuldades da educação são sempre relacionadas ao próprio processo educativo" (Lopes 2002).
\end{abstract}

Em outras palavras, o tecnicismo consistiria de propostas de mudança somente no aparato técnico-pedagógico, não no estrutural, cultural ou político. Muitos projetos de uso do computador no ensino adotam o cenário de busca pela eficiência no ensino, ora sob influências construtivistas, ora sob argumentos tecnicistas, ora a serviço do ensino tradicional, em que, para transmissão de conteúdos, o computador substitui o livro ou o professor.

Entretanto, neste trabalho desenvolvido em Geociências, o uso do computador leva em conta, principalmente, as especificidades do raciocínio geológico.

Ensino de Geociências: o raciocínio geológico e sua linguagem visual No ensino fundamental, os estudantes deveriam ter idéia dos processos e mecanismos da evolução do planeta, externos ou internos, e a contínua interação entre atmosfera, hidrosfera, litosfera e biosfera, mas o programa de Ciências é fragmentário, o livro didático não fornece visão integrada da Terra, e o professor é incapaz de descrever aos alunos "o mundo em que vivemos, sua origem, evolução e destino" (Campos 1997), em virtude de deficiências da própria formação acadêmica que recebeu. Normalmente o primeiro e último contato com esse conteúdo se faz em uma única disciplina do currículo de graduação denominada "Introdução às Geociências", "Geologia Geral" ou equivalente (Compiani e Cunha 1992). Além da formação acadêmica do professor, devem ser consideradas questões relacionadas à gestão escolar, currículo, autonomia docente, opções ideológicas, políticas educacionais etc.

$\mathrm{O}$ ensino de ciências predominante na educação básica brasileira obedece a métodos autoritários e centralizadores que "confinam" o aluno, a quem cabe memorizar e repetir as informações transmitidas pelo professor, simplesmente tomando conhecimento do produto final da atividade científica. $\mathrm{O}$ aluno não tem idéia da complexidade dos processos envolvidos nessa produção (Lopes 2002). Até mesmo os recursos didá- ticos de apoio, embora não tenham sido criados com essa finalidade, podem reforçar tal abordagem. O livro passou de auxiliar didático a orientador exclusivo das aulas (Fracalanza et al. 1986); atividades em laboratórios de ciências, quando existem, ocorrem por meio de etapas conduzidas sem erro para mostrar que a teoria é verdadeira. Assim, tanto alunos quanto professores convivem com a idéia de que a ciência é consensual, livre de divergências e somente conduz à verdade.

A informática já se reveste, em parte, das mesmas características de outros recursos didáticos, até por se tratar do insumo mais recente para ensino de ciências. Em diversos softwares educativos de ciências predomina a transmissão de conteúdos, sem levar em conta especificidades do ambiente escolar.

A Geologia ocupa posições periféricas no currículo da escola básica, embora represente a própria "alfabetização na linguagem da natureza" (Compiani 1990, p. 115). Tal conhecimento auxiliaria muito a compreensão do funcionamento do planeta, impulsionado pela visão de Ciência do Sistema Terra, que procura integrar as esferas terrestres e revelar suas interações (Carneiro et al. 2005, Mayer 2002, Gonçalves e Carneiro 2002).

RACIOCÍNIO GEOLÓGICO Gilbert (1887) e Chamberlain (1887) descrevem procedimentos metodológicos clássicos da literatura geológica. Para Gilbert (1887) o conhecimento científico ganha com o advento de uma nova teoria, mesmo que ela não seja mais tarde comprovada. Sempre que possível, diferentes hipóteses podem e devem ser testadas ao mesmo tempo; mesmo sendo mais tarde rejeitadas, não deixam de ter valor, pois se aprende com o erro. Na época, Chamberlain (1887) formula o Método das Múltiplas Hipóteses de Trabalho, que propõe devam ser avaliadas várias causas para um dado fenômeno, com a possibilidade de várias ou nenhuma delas ser aceita. O procedimento implica visão simultânea de diferentes pontos de vista e descarta raciocínios lineares.

Potapova (1968) destaca que a geologia é uma "ciência histórica da natureza" por estudar o desenvolvimento histórico dos processos naturais "fixados" na crosta terrestre e dependentes de métodos de investigação histórico-comparativos. Frodeman (2001) reforça o caráter da Geologia como ciência histórica e interpretativa, na qual o raciocínio é apoiado em analogias e as explicações freqüentemente não são verificáveis. Segundo Frodeman, esse modelo de pensamento nos ajuda a lidar com a realidade:

\footnotetext{
"O modelo de pensamento científico tipificado pelos geólogos é mais aplicável às incertezas e complexidades das nossas vidas. Raramente possuímos todos os dados para tomar decisão e nem sempre é claro que os dados são objetivos ou imparciais. Somos forçados a preencher as lacunas do nosso conhecimento com interpretações e afirmações plausíveis que esperamos virem a ser posteriormente confirmadas. Desta forma, os métodos de uma ciência hermenêutica e histórica refletem melhor
} 
as complexidades que enfrentamos enquanto seres históricos".

Nas Geociências o raciocínio requerido é essencialmente histórico-comparativo, apoiado na observação visual dos fenômenos e de seus registros diretos e indiretos, além da ênfase em explicações hipotéticas e na comunicação narrativa. Assim, os procedimentos metodológicos típicos da Geologia, como múltiplas hipóteses explicativas, visualidade, raciocínio histórico e analógico, valorização da interpretação e imaginação, expressos por Chamberlain, Potapova, Frodeman e outros, afastam-na das ciências experimentais "clássicas" como a Física e a Química.

A Geologia utiliza amplamente a linguagem visual, cujas raízes são anteriores à formalização da própria Geologia como ciência. Aprofundando a associação entre símbolos, signos e a geologia, Paschoale (1989) desenvolve a idéia da geologia como a "semiótica da natureza".

Diversos estudos validam a transposição didática do raciocínio geológico para os níveis de ensino fundamental e médio. Segundo Compiani (1993), que se reporta a Chamberlain (1887), essa contribuição reside no estímulo à formulação de hipóteses e raciocínios baseados na correlação, ao desenvolvimento da capacidade de formular explicações causais múltiplas em oposição ao raciocínio causal linear simples a que os estudantes estão habituados, tanto na explicação de fenômenos científicos, quanto do cotidiano. A linguagem visual é fortemente vinculada ao raciocínio geológico, mesmo porque a própria geologia está intimamente relacionada a representações gráficas (Anguita 2005). A linguagem visual favorece a imaginação e a contextualização, bem como o pensamento intuitivo, e mereceria maior atenção no ensino (Compiani 1997, 2006).

Por outro lado, os estudos geológicos realizados no final do século XIX, para interpretação da dinâmica dos sistemas terrestres, quando comparados aos do início do século XXI, envolvem volumes de dados e informações significativamente menores. $O$ exponencial crescimento no aporte de dados introduziu a necessidade de ferramentas computacionais potentes para acumular, gerenciar e processar dados, em um processo auto-alimentador, que viabilizou o aumento do volume de informações sobre o planeta.

Toledo (comunicação oral) salienta que, enquanto as novas tecnologias desenvolveram muito as práticas em Geologia, não se observam reflexos desse avanço no ensino de Geociências na escola: as disciplinas focalizam a dinâmica ambiental, mas pouco contribuem para conceituar os ecossistemas.

Imagens geológicas e computadores no ensino As imagens na educação científica podem gerar oportunidades para o indivíduo pensar, organizar idéias, construir analogias e atitudes inquiridoras (Amador 1998). O uso mais interessante de imagens no ensino ocorre quando a imagem assume função "epistemológica", associada a processos de construção do saber por meio de geração de idéias e elaboração de hipóteses explicativas, conforme exemplificado pelas fotos de duna (Fig. 1). Ademais, imagens constituem mediações, por vezes apagadas, da relação homem-mundo, sujeito-realidade (Silva 2006).

É de se supor que resida na capacidade de veiculação e processamento de imagens a maior contribuição do computador ao raciocínio geológico, uma vez que a rotina de trabalho de pesquisa em Geologia e a formação acadêmica de novos geólogos é apoiada fortemente no processamento de imagens, como sensoriamento remoto, cartografia digital e Sistemas de Informações Georreferenciadas (SIGs).

LINGUAGEM VISUAL Levantamento sobre utilização de imagens no ensino mostra que professores reconhecem múltiplas funções pedagógicas com forte caráter motivador, mas ainda predomina o uso ilustrativo das imagens (Pimentel 2001), com as funções de identificação, descrição e reconhecimento, em prejuízo da interpretação, comparação e análise.

As dificuldades apontadas pelos professores em lidar com imagens residem mais em aspectos de ordem estrutural, como equipamentos não-apropriados, escassez de material de apoio, custos de aquisição, entre outros, do que em aspectos metodológicos ou que digam respeito ao reconhecimento da insuficiência dos próprios professores no domínio da linguagem visual (Pimentel 2001, Calado 1994). A falta de maior formalização da linguagem visual para o ensino é um obstáculo na capacitação dos professores (Calado 1994). O problema de lidar criativamente com imagens escapa da vontade do professor, pois a escola tem dificuldade em lidar com linguagens que não sejam as tradicionais (Tardy 1976, Amador 1998, Lévy 1999).

Dentre as dificuldades apontadas por professores para utilização de imagens no ensino estão a escassez de material, os altos custos de reprodução e estrutura logística necessária para sua veiculação. $\mathrm{O}$ uso do computador em aula poderia amenizar alguns desses entraves - bastaria certa organização e estrutura de computadores com acesso à Internet para uso mais rico de imagens no ensino. Entretanto, a contribuição seria vaga, pois não incide diretamente na valorização do raciocínio geológico.

Há competências associadas à linguagem visual que poderiam ser mais bem exploradas se o professor lidasse com as técnicas para geração de imagens (Amador 1998, Calado 1994), pois a capacidade de gerar imagens afeta a própria percepção do sujeito sobre elas. O computador, como ferramenta de edição e produção de imagens, enriqueceria o ensino, ultrapassando usos ilustrativos ou motivadores (Compiani e Carneiro 1993), na medida em que o conceito de "imaginação" significa habilidade para produzir imagens e o computador potencializa tal produção e aprimora a linguagem visual.

Entretanto, a contribuição do computador não se limita às imagens estáticas. No extremo oposto estão as simulações complexas, que incluem imagens des- 
vinculadas de cenas naturais, como modelos de dinâmica demográfica, evolução das espécies, ecossistemas (Lévy 1999). O computador pode oferecer alto grau de interação com imagens, sendo suporte a modelos dinâmicos em duas ou três dimensões ou facilitar a construção de ambientes simulados: os "experimentos mentais" (Matthews 1994). Há grande variedade de incertezas, dificuldades e desafios para o professor e para a escola tanto na imagem estática no computador (fotografia, imagem de satélite, mapa, desenho...) como nas simulações complexas e interativas.

Mais reflexão e experiência com o ensinoaprendizagem empregando-se imagens são necessárias para explorar o potencial educativo do raciocínio geológico ou para promover a alfabetização visual, em alguma "pedagogia das imagens". Se a educação depende de quem está conduzindo o processo, de onde e em qual contexto este se dá, a ênfase deve deslocar-se do instrumento de suporte (o computador) para a capacitação do elemento humano que o utiliza (o professor) sem desconsiderar a cultura, sociedade, ideologia e política.

CARACTERÍSTICAS DO PROJETO GEO-ESCOLA O projeto Geo-Escola divide-se em módulos regionais, baseados em computador, apoiados em softwares de arquitetura aberta, que permitem que professores de educação básica das disciplinas Geografia, Ciências e outras tenham acesso a informações, imagens e mapas geológicos de uma dada região. A proposta de uso intensivo do computador como ferramenta de ensino parte da premissa de que conceitos geológicos básicos sustentam a aquisição de conhecimentos específicos da região abordada; todo módulo oferece materiais didáticos para a sala-de-aula.

Módulo Jundiaí-Atibaia O primeiro módulo buscou auxiliar o trabalho do professor de Ciências e Geografia da escola fundamental ( $5^{\mathrm{a}}$ a $8^{\mathrm{a}}$ séries $)$ de dez municípios situados a norte da capital paulista: Jundiaí, Atibaia, Mairiporã, Franco da Rocha, Francisco Morato, Cajamar, Várzea Paulista, Jarinu e Campo Limpo Paulista. Com a proposta de difusão de informações sobre temas locais (e regionais) para apoio aos programas das disciplinas, pesquisou-se o interesse de professores por conceitos básicos e temas regionais. O questionário remetido a 168 escolas públicas e privadas solicitou que os professores classificassem temas considerados mais importantes em Geociências de uma lista inicial de 15 (Tab. 1). Devido a razões de abrangência e maior especificidade de conteúdos veiculados, o nível médio de escolaridade não foi considerado na proposta inicial desse módulo.

Foram recebidas respostas de 108 professores, de um total de 49 escolas. A amostra é significativa, pois perfaz aproximadamente $30 \%$ do universo consultado. Os professores revelaram grande interesse por assuntos geocientíficos e valorizaram aspectos da dinâmica ambiental local. No entorno das cidades de Campo Limpo, Várzea Paulista, Atibaia e Jundiaí, a rápida expansão urbana gera efeitos intensos de degradação ambiental.
O interesse das informações para a população que vive na região é direto, porque os processos podem afetá-los diretamente, a exemplo dos processos de erosão acelerada, que chegam a criar situações de risco em loteamentos de alguns municípios.

Os resultados permitiram que a equipe produzisse um CD-ROM a partir de levantamentos geológicos em escalas de semi-detalhe. Os textos técnicos e conceitos especializados foram reescritos e as imagens, selecionadas e descritas por intermédio de ferramenta auxiliar, presente no CD, denominada Álbum de Fotografias (Carneiro e Barbosa 2003).

O desenvolvimento desse módulo foi prejudicado por alguns fatores (Barbosa 2003) como: falta de interação com professores, insuficiente coleta de dados sobre a avaliação destes sobre o material enviado e sobre emprego da informática na escola. Concluiu-se que o trabalho dos professores foi dificultado por deficiências conceituais em Geociências, que limitam o aproveitamento de conhecimentos sobre a história geológica (Barbosa 2003).

Módulo São José do Rio Preto O segundo módulo compreende atividades de professores de Ciências e Geografia das escolas fundamental e média de um único município, São José do Rio Preto (SP). Um questionário mais completo que o do módulo Jundiaí-Atibaia foi enviado a 92 escolas públicas e privadas da educação básica. Atingiu-se amostra mais significativa que o Módulo Jundiaí-Atibaia, aproximadamente $46 \%$ do universo consultado. De um total de 42 escolas, 116 professores selecionaram tópicos de Geociências considerados mais importantes de uma lista de 22 temas (Tab. 2).

A pesquisa incluiu temas sobre água e ambiente, graças a uma base de dados (Piranha et al. 2004, Piranha e Pacheco 2004), contendo informações detalhadas das reservas hídricas no município, abastecimento público de água, e fontes potenciais de degradação dos mananciais em virtude da ocupação urbana. As informações foram ordenadas em banco de imagens fotográficas (álbum de fotografias), mapas temáticos e texto descritivo da situação do município frente à ocupação. O CD-ROM (Carneiro et al. 2004b) resultante foi utilizado, como material didático, pelos professores participantes.

O trabalho com professores transcorreu em sucessivos encontros, alguns na forma de cursos de extensão (Tab. 3), do qual participaram 46 professores durante 2004. Este módulo envolveu forte interação com professores. A coleta de dados foi abrangente, compreendendo impressões destes sobre a importância dos cursos oferecidos, dos trabalhos de campo, dos materiais didáticos e até mesmo o grau de utilização de informática em aulas.

A avaliação do material fornecido compreende a avaliação do uso dos programas de computador, a assimilação de conceitos desenvolvidos nas várias atividades e sua aplicação em situações reais. A estratégia adotada envolve questionários dirigidos aos docentes, 
Tabela 1 - Temas de geociências utilizados na consulta de interesse do Módulo 1.

\begin{tabular}{c|l}
\hline$N^{\circ}$ & TEMA \\
\hline 1 & Relevo, topografia, localização espacial, mapas \\
\hline 2 & Minerais e classificação de rochas \\
\hline 3 & Formação do Universo e da Terra \\
\hline 4 & $\begin{array}{l}\text { Eclipses, meteoros, estações do ano, dados sobre o } \\
\text { Sistema Solar e seus planetas }\end{array}$ \\
\hline 5 & História geológica do planeta \\
\hline 6 & Tempo geológico \\
\hline 7 & Ciclos da natureza \\
\hline 9 & Água, rios e ciclo hidrológico \\
\hline 10 & Esferas da Terra, placas tectônicas, vulcões, terremotos \\
\hline 11 & $\begin{array}{l}\text { Intemperismo e solos, tipos de solo, movimentos do } \\
\text { solo }\end{array}$ \\
\hline 12 & Riscos de acidentes naturais e ocupação urbana \\
\hline 13 & $\begin{array}{l}\text { Geologia e evolução geológica da região de Jundiaí- } \\
\text { Atibaia }\end{array}$ \\
\hline 14 & $\begin{array}{l}\text { Relevo da região de Jundiaí-Atibaia e problemas de } \\
\text { ocupação urbana }\end{array}$ \\
\hline 15 & $\begin{array}{l}\text { Estudos do meio e trabalhos de campo na região de } \\
\text { Jundiaí-Atibaia }\end{array}$ \\
\hline
\end{tabular}

Tabela 2 - Temas de geociências utilizados na consulta de interesse do Módulo 2.

\begin{tabular}{c|l}
\hline $\mathrm{N}^{\circ}$ & TEMA \\
\hline 1 & Formação do Universo e da Terra \\
\hline 2 & $\begin{array}{l}\text { Esferas da Terra, placas tectônicas e migração dos } \\
\text { continentes }\end{array}$ \\
\hline 3 & Vulcanismo e terremotos \\
\hline 4 & $\begin{array}{l}\text { Minerais e rochas: ocorrências no Brasil, identificação, } \\
\text { coleções }\end{array}$ \\
\hline 5 & Recursos minerais e fontes de energia \\
\hline 6 & Tempo geológico e fósseis \\
\hline 7 & Formação dos solos e intemperismo \\
\hline 8 & Erosão natural, acelerada e assoreamento \\
\hline 9 & Ciclos na natureza \\
\hline 10 & Água no ambiente \\
\hline 11 & Ciclo da água \\
\hline 12 & Águas superficiais: rios, lagos, oceanos e geleiras \\
\hline 13 & Águas subterrâneas \\
\hline 14 & Poluição e contaminação ambiental \\
\hline 15 & $\begin{array}{l}\text { Fontes de contaminação das águas em meio urbano e } \\
\text { rural }\end{array}$ \\
\hline 16 & Uso racional da água \\
\hline 17 & Controle de impactos ambientais \\
\hline 18 & Riscos de acidentes naturais \\
\hline 19 & Lixo: aterros, lixões, tratamentos e reaproveitamento \\
\hline 20 & Recursos naturais e o desenvolvimento sustentável \\
\hline 21 & Geologia da região de São José do Rio Preto \\
\hline 22 & Roteiros de campo para Educação Ambiental \\
\hline & \\
\hline
\end{tabular}

entrevistas pessoais e participação direta dos pesquisadores em atividades nas escolas participantes do projeto. Piranha (2006) indica que o trabalho foi eficaz para aproveitamento de dados sobre a história geológica da Bacia do Paraná, dinâmica natural local, e problemática ambiental vivida pelo município. Inúmeras apresentações, produzidas por alunos e docentes confirmam amplamente que se fomentou o desenvolvimento de estudos sobre temas ambientais. Pode-se dizer que nesta experiência houve uma "internalização" do projeto, na forma de um "Projeto Geo-Escola na Escola", que interessou até mesmo a docentes de outras áreas, além de Ciências e Geografia.

Módulo Campinas O módulo mais recente da pesquisa acha-se em desenvolvimento em escolas da cidade de Campinas (SP). Contrariamente à estratégia anterior, inexistiu consulta inicial sobre temas a ser priorizados por professores. Um motivo é a ausência, neste caso, de levantamentos geológicos de semi-detalhe ou bases plani-altimétricas digitais recentes. Os mapas geológico e geomorfológico disponíveis acham-se em escalas de semi-detalhe e regional, respectivamente.

A eventual produção de um CD-ROM será precedida pela obtenção de dados de campo específicos sobre geologia local e problemas ambientais do município. O projeto Geo-Escola oferecerá, como nos demais módulos, ferramentas de software aberto e estimulará a difusão do uso dos equipamentos e dos programas. As primeiras atividades conduzidas revelam que os laboratórios de informática instalados estavam em desuso, devido à falta de iniciativas dirigidas ao ambiente escolar. Em poucos meses de envolvimento, foi possível reativá-los, em etapa importante rumo ao aproveitamento da capacidade instalada e conscientização de alunos e professores sobre Geociências.

DISCUSSÃO O computador disseminou-se na produção de material didático para a sala-de-aula, mas esse uso é ainda incipiente. Recursos como apresentações padronizadas contendo imagens criam atmosfera familiar e, em sua produção, favorecem o envolvimento de especialistas capazes de decodificar conceitos básicos a partir de mapas e relatórios. É importante a etapa de seleção de temas de Geociências pelos professores, mas o Projeto Geo-Escola depende sobretudo do acesso dos usuários aos materiais didáticos, da possibilidade de reproduzí-los nos equipamentos existentes nas escolas, e da existência de algum interesse reconhecido.

O professor pode selecionar noções fundamentais para $\mathrm{o}$ ato de ensinar, mas sofre limitações. O papel da universidade nesse contexto consiste na decodificação do conhecimento, para propiciar rica interação entre professores do ensino básico e universitários (Meis et al. 1997). São pontos relevantes da iniciativa o aproveitamento de dados básicos sobre a história geológica e dinâmica ambiental da região e a possibilidade de trabalhar em diferentes escalas, especialmente considerando-se a região onde os professores vivem ou exercem seu trabalho educativo.

A principal limitação dos trabalhos tem sido o tempo disponível dos docentes para capacitação, atividade em que houve grande investimento de tempo no 
Tabela 3 - Cursos teórico-práticos desenvolvidos no Módulo São José do Rio Preto.

\begin{tabular}{l|l|l}
\hline \multicolumn{1}{c|}{ Curso } & \multicolumn{1}{c}{ Local } \\
\hline C1 & Uso do computador no ensino & Laboratório Didático \\
\hline C2 & Uso do Editor Geo-Escola & Laboratório Didático \\
\hline C3 & Temas de Geociências (referenciais teóricos) & Sala-de-aula \\
\hline C4 & Temas de Geociências (referenciais práticos em campo) & Área rural e urbana de SJRP \\
\hline C5 & Temas de Geociências (referenciais práticos em campo) & Região Noroeste do Estado de SP \\
\hline C6 & Temas de Geociências (referenciais práticos em campo) & SJRP - São Paulo - litoral paulista \\
\hline
\end{tabular}

módulo São José do Rio Preto, com ótimos resultados. A avaliação dos CD-ROMs educacionais do projeto Geo-Escola está em andamento, devendo ser referência importante a produção de materiais didáticos pelos professores e a investigação das alternativas por eles escolhidas para incluir a realidade local em sua prática com alunos. A avaliação envolverá parâmetros como a utilidade dos materiais - em diferentes situações de ensino-aprendizagem e diversas séries escolares - e o estímulo promovido aos estudos de campo (os chamados estudos do meio) considerando-se informações de natureza geológica (Carneiro e Barbosa 2005).

Geologia na Sala-de-Aula Professores de Geografia e Ciências necessitam de numerosos conceitos de Geologia para alcançar um entendimento mínimo da evolução de determinada região e das características do substrato rochoso regional. Descrições da geologia e geomorfologia locais podem interessar à população, aspecto salientado por diversos autores. Os três módulos do Projeto Geo-Escola fazem parte de um movimento orientado nessa direção, do qual são bons exemplos: Lacreu e Sosa (2000), que descrevem características marcantes do relevo e da história geológica da região de San Luis, Argentina, e Piacente e Giusti (2000), que desenvolvem na Itália o conceito de Geotopos, áreas cujo patrimônio natural é de grande valor para compreensão da História da Terra.

Algum grau de aprofundamento conceitual deveria existir para acesso às peculiaridades do raciocínio geológico e habilitar os professores a trabalhar tais conteúdos. Outras barreiras importantes são a escassez de material didático, e o problema da mudança de abordagem no ensino de Ciências e de Geografia, que possibilite participação mais ativa do aluno. As sugestões de professores e as falas de alunos indicam que temas de Geociências podem ser aproveitados para discussão em sala-de-aula. É necessário garantir flexibilidade para elaboração de propostas específicas para cada realidade (Fracalanza et al. 1986). Uma vez que a orientação dos PCNs valoriza o cotidiano dos alunos e do ambiente onde vivem, pode-se concluir que há muito espaço para que o professor e a escola tenham liberdade para elaborar propostas voltadas a interesses locais.

O Projeto Geo-Escola buscou ainda viabilizar a elaboração, pelo professor, de material didático regional de apoio, o que conduz a outro relevante tema, a autonomia do professor, questão complexa de âmbito mais político do que técnico (Matthews 1994). Projetos nacionais como o PROINFO, combinados às diretrizes dos PCNs, reacendem o interesse pelo tema, mas ultrapassam o escopo do presente artigo.

Uma "entrada" dos computadores nas escolas poderia decorrer da reflexão sobre currículo e conteúdos científicos de interesse local. Enquanto as ferramentas computacionais são relativamente fáceis de acessar, raramente disponibilizam-se informações sobre ambiente local para os docentes, exceto durante cursos de reciclagem e aprimoramento. O caminho de aliar a informática ao ensino de Geociências nas escolas seria um germe contra a padronização reinante de conteúdos, rumo a uma contribuição à cidadania e à democracia, graças à regionalização de currículos.

COMENTÁRIOS FINAIS A experiência acumulada pelo Projeto Geo-Escola permite afirmar que é viável e oportuna a elaboração de materiais didáticos a partir de informações obtidas em projetos de investigação e mapeamento geológico regional em escalas de detalhe e semi-detalhe. Da profícua interação de professores de Ciências e Geografia com os especialistas, que decodificam conceitos básicos a partir da massa disponível de informações, decorre importante papel multiplicador, que abre espaço para a regionalização de currículos. Os módulos (1) Jundiaí-Atibaia, (2) São José do Rio Preto e (3) Campinas, situados no Estado de São Paulo, continuam a despertar interesse de docentes em vários níveis de ensino.

Os benefícios que o computador oferece na escola superam de longe as incertezas geradas. Os excelentes resultados obtidos em São José do Rio Preto sugerem que a ênfase deva ser deslocada para a capacitação do professor, já que a educação depende sobretudo do condutor do processo e do contexto em que ocorre. A equipe tem sido receptiva a novos desenvolvimentos e aplicações que levem em conta outras situações geológicas. O incentivo ao uso do computador como ferramenta educativa pela comunidade nacional de Geologia parece estar apenas se iniciando. A promissora interação junto a professores é capaz de expandir a difusão das Geociências, importante recomendação do Fórum Nacional de Cursos de Geologia (Assis e Lazzarotto 2006); nessa direção, a linha proposta pelo Projeto Geo-Escola é beneficiada pelas magníficas condições naturais e a variedade de ambientes existentes no país.

Agradecimentos Os autores agradecem aos professo- 
res e alunos participantes dos vários módulos acima referidos; agradecem especialmente a cuidadosa revisão, feita por um relator anônimo da RBG, cujas sugestões ajudaram a aprimorar o trabalho.

\section{Referências}

Amador F. 1998. As imagens no ensino da Geologia. Aveiro, Univ. Aveiro. n. 2. (Fm. Professores, cadernos didácticos, Série Ciências).

Amaral I.A.do. 1991. Ambiente, educação ambiental e ensino de Ciências. In: M.M.S.de Lima, N.M.M. Kiouranis, R.C.E.G. Gonçalves, S.M.A. Alencar (eds.) Ciências na escola de $1^{\circ} \mathrm{Grau}$. Textos de apoio à proposta curricular. São Paulo, Secret. Est. Educação, Coord. Estudos e Normas Pedagógicas, p. 39-62.

Anguita Virela F. 2005. El Power Point en el aula (de Geología): punto y final del aprendizage crítico? Rev. de la Enseñanza de las Ciencias de la Tierra, 13(2):190-192.

Assis J.F.P., Lazzarotto A. 2006. Relato Final do V Encontro do Fórum Nacional de Cursos de Geologia, Cuiabá, junho de 2005. Terrce Didatica, 2(1):91-104. Disponível em: http:// www.ige.unicamp.br/terraedidatica/. Acessado em 15 fev. 2007.

Barbosa R. 2003. Projeto Geo-Escola: recursos computacionais de apoio ao ensino de geociências nos níveis fundamental e médio. Dissertação Mestrado, Inst. Geoc., Univ. Est. Campinas, $105 \mathrm{p}$.

Belloni M.L. 1999. Educação à distância. Campinas, Autores Associados, 126p.

Brasil. Ministério da Educação. Secretaria de Educação Média e Tecnológica. 1999. Parâmetros Curriculares Nacionais: Ensino Médio. Brasília, Ministério da Educação, $364 \mathrm{p}$.

Calado I. 1994. A utilização educativa das imagens. Ed. Porto, Porto, 126p.

Campos D.A. 1997. O ensino das ciências da Terra. In: Acad. Bras. Ciências, Simpósio a Importância da Ciência para o Desenvolvimento Nacional, 1, São Paulo, Documentos, p. 39-46. (1a. sessão, Educação).

Carmo A.S. 2004. O uso da Informática como ferramenta pedagógica no desenvolvimento de conteúdos de Geociências no ensino fundamental. Dissertação Mestrado, Inst. Geoc., Univ. Est. Campinas, 86p.

Carneiro C.D.R. \& Barbosa R. 2002. Demandas de conocimiento de geociencias por profesores de Ciencias y Geografia: el ejemplo de Jundiaí-Atibaia, São Paulo, Brasil. In: AEPECT, Simp. de la Enseñanza de la Geología, 12, Girona. Actas, p. 47-57. (Documentos de Trabajo).

Carneiro C.D.R. \& Barbosa R. 2003. A simple didactic tool for stimulating the use of computers in Geology Education. In: IGEO, GeoSciEd, Intern. Conf. on Geosc. Education, 4, Calgary, Alberta, Canada, Conference Proceedings, p. 25-26.

Carneiro C.D.R. \& Barbosa R. 2005. Geo-escola: disseminação de conteúdos de Geociências por meio do computador para docentes de Ciências e Geografia no Nível Fundamental em Jundiaí-Atibaia, SP. Geologia USP - Série Didática, Publ. Espec., 3:71-82.

Carneiro C.D.R., Barbosa R., Piranha J.M. 2004a. Using computers to improve Earth Sciences education in Bra- zilian high-schools: the Geo-School Project. In: Intern. Geol. Congr., 32, Florence, Abstracts, Pres. 292-3. (CDROM, Sci. Sessions: abstracts, part $2-1300$ ).

Carneiro C.D.R., Gonçalves P.W., Negrão O.B.M., Cunha C.A.L. 2005. Ciência do Sistema Terra e o entendimento da "máquina" planetária em que vivemos. Geonomos, 13(1):11-18.

Carneiro C.D.R., Piranha J.M., Barbosa, R. 2004b. Projeto Geo-Escola. Materiais Didáticos em Geociências com suporte no computador. Módulo São José do Rio Preto, Estado de São Paulo. São José do Rio Preto, UNESP e Unicamp (CD-ROM: Windows XP).

Carneiro C.D.R., Toledo M.C.M.de, Almeida F.F.M. de. 2004c. Dez motivos para a inclusão de temas de Geologia na Educação Básica. Rev. Bras. Geoc., 34(4):553560.

Chamberlain T.C. 1887. The method of multiple working hypotheses. J. Geol. 1887. (Reproduzido em Science, 148:754-759, http://arti.vub.ac.be/cursus/20052006/mwo/chamberlin1890science.pdf. Acesso em 13.11.2007.

Chamberlin T. C. 1965. The Method of Multiple Working Hypotheses. With this method the dangers of parental affection for a favorite theory can be circumvented. Science, 148:754-759.

Compiani M. 1990. A Geologia pra que te quero no ensino de ciências. Educação e Sociedade, (36):100-117.

Compiani M. 1993. O papel do método das múltiplas hipóteses de trabalho no ensino de geociências. Enseñanza de las Ciencias. Madrid, 1993. (n. extra) (IV Congresso).

Compiani M. 1997. Os aspectos visuais e espaciais no ensino de Geociências. O uso dos desenhos. Ensenanza de las Ciencias. Madrid, 1997. (n. extra):329-330. (V congreso).

Compiani M. 2006. Linguagem e percepção visual no ensino de Geociências. Pro-Posições, 17(1):85-104.

Compiani M. \& Carneiro C.D.R. 1993. Os papéis didáticos das excursões geológicas. Rev. de la Enseñanza de las Ciencias de la Tierra, 1(2):90-98.

Compiani M., Cunha C.A.L.S. 1992. O ensino de Geociências nos 3 graus de escolaridade - um panorama do Brasil. In: Congresso Geologia de España, 3, y Congresso Latinoamericano de Geologia, 8, Salamanca, Actas, tomo I, p.324-352.

Earth Science Curriculum Project (ESCP). 1973. Investigando a Terra. Mc Graw Hill do Brasil, São Paulo, v. 1, $435 \mathrm{p}$.

Ferrés J. 1998. Pedagogia dos meios audiovisuais e pedagogia com os meios audiovisuais. In: J.Sancho (org.) Para uma tecnologia educacional. Porto Alegre, ArtMed., p. $132-155$.

Fracalanza H., Amaral I.A.do, Gouveia M.S.F. 1986. O Ensino de Ciências no Primeiro Grau. Atual, São Paulo, $124 \mathrm{p}$. 
Frodeman R. 2001. A epistemologia das geociências. In: L.Marques \& J. Praia (coords.) Geociências nos currículos dos ensinos básicos e secundário. Aveiro, Universidade de Aveiro, p. 39-57.

Gilbert G.K. 1887. The inculcation of scientific method by example, with an illustration drawn from the Quaternary Geology of Utah. Am. J. Sci., XXXI(181-186):284-299.

Globe Project. 2003. What is the GLOBE Program? Washington, DC: GLOBE Project. Disponível em: http://www.globe.gov/fsl/html/aboutglobe.cgi? intro\&lang $=e n \& n a v=1$. Acesso em 10 fev. 2003.

Gonçalves P.W., Carneiro C.D.R. 2002. Global Science Literacy: from Geology teaching to Earth System Science teaching. In: V.J. Mayer (ed.) Implementing Global Science Literacy. Columbus, Ohio, Earth Systems Education Program/The Ohio State Univ., v. 2, p. 203-220. (Cap. 14).

Lacreu H., Sosa G.R. 2000. The history of the landscape that surrounds my city. San Luis, Argentina. In: GEOSCIED, Intern. Conf. on Geosc. Education, 3, Sidney, Austrália, Abstract Vol., p. 60. (errata avulsa).

Lévy P. 1999. Cibercultura. Ed. 34, São Paulo, 260p.

Lopes J.C. 2002. O que há por trás da busca pela melhoria do ensino: um projeto educacional em Geologia. Dissertação de Mestrado, Fac. Educação, Univ. Est. Campinas, $105 \mathrm{p}$.

Massetto M.T. 2003. Mediação pedagógica e o uso da tecnologia. In: J.M. Moran, M.T. Massetto, M.A. Behrens (eds.) Novas tecnologias e mediação pedagógica. $6^{\mathrm{a}}$ ed., Campinas, Papirus, p.133-173.

Matthews M.R. 1994. Science teaching. The Role of History and Philosophy of Science. Routledge, New York, 308p.

Mayer V.J. 2002. Global Science Literacy: a theoretical and conceptual foundation for science curricula. In: V.J. Mayer (ed.) Implementing Global Science Literacy. Columbus, Ohio, Earth Systems Education Program/The Ohio State Univ., v. 2, p. 5-22. (Cap. 1).

Meis L.de, Leta J., Lannes D. 1997. O ensino de ciências face à explosão do saber. In: Acad. Bras. Ciências, Simpósio A importância da ciência para o desenvolvimento nacional, 1, São Paulo, Actas, p. 29-37. (1a. sessão, Educação).

Meis L.de, Leta J., Lannes D. 1997. O ensino de ciências face à explosão do saber. In: Acad. Bras. Ciências, Simpósio A importância da ciência para o desenvolvimento nacional, 1, São Paulo. Documentos, p. 29-37. (1a. sessão, Educação).

Oppenheimer T. 1997. The computer delusion. Atlantic Monthly, 280(1):45-62.

Paschoale C. 1989. Geologia como semiótica da natureza. Dissertação Mestrado, Pós-Grad. em Comunicação e Semiótica, Pontifícia Universidade Católica, 195p.

Paschoale C., Freitas H.C.L.de, Fracalanza H., Amaral
I.A.do, Tessler M.G. 1981. A geologia e a escola de $1^{\circ}$ e $2^{\circ}$ graus. In: SBG, Simpósio Nacional sobre o Ensino de Geologia no Brasil, 1, Belo Horizonte. Teses, v. 1, p. 157-167.

Piacente S. \& Giusti C. 2000. Geotopos una oportunidad para la difusion y valoracion de la cultura geologica regional. In: AEPECT, Simposio Enseñanza de la Geología, 10, Santander, Actas, p. 134-137.

Pimentel C.S. 2001. A imagem no ensino de geografia: a prática dos professores da rede pública estadual de Ponta Grossa, Paraná. Dissertação Mestrado, Inst. Geoc., Univ. Est. Campinas, 126p.

Piranha J.M. 2006. O ensino de geologia como instrumento formador de uma cultura de sustentabilidade: o Projeto Geo-Escola em São José do Rio Preto, SP. Tese de Doutoramento, Inst. Geoc., Univ. Est. Campinas, 105p.

Piranha J.M. \& Pacheco A. 2004. Recursos Hídricos e Desenvolvimento - Diagnóstico básico preliminar do município de São José do Rio Preto. In: Associação Brasileira de Águas Subterrâneas, Congresso Brasileiro de águas subterrâneas, 13, Cuiabá, Anais, (CD-ROM).

Piranha J.M., Pacheco A., Carneiro C.D.R., Rebouças A.C., Antonello S.L. 2004. Recursos Hídricos e Desenvolvimento. Diagnóstico básico preliminar do município de São José do Rio Preto. São José do Rio Preto, UNESP, USP e UNICAMP. (CD-ROM: Windows XP).

Potapova M.S. 1968. Geology as an historical science of nature. In: Interaction of the science in the study of the Earth Progress, Moscow, p. 117-126.

Sancho J. org. 1998. Para uma tecnologia educacional. ArtMed, Porto Alegre, 327p.

Saviani D. 2000. Escola e democracia: teorias da educação, curvatura da vara, onze teses sobre a educação política. 33 ed. Autores Associados, Campinas. (Col. Polêmicas do Nosso Tempo; v. 5). 94p.

Silva H.C.da. 2006. Lendo imagens na educação científica: construção e realidade. Pro-Posições, Campinas, 17(1):71-83.

Skinner B.F. 1975. Tecnologia do Ensino. Ed. Pedagógica e Universitária/EDUSP, São Paulo, 260p.

Tardy M. 1976. O professor e as imagens. Cultrix/EDUSP, São Paulo, 195p.

Toledo M.C.M. comunicação oral. Geologia/Geociências no Ensino. In: SEMINÁRIO nacional sobre cursos de geologia, 1, 24 a 26 de abril de 2002. Campinas: Universidade Estadual de Campinas. (Apres. oral).

Wagensberg J. 2002. Si la naturaleza es la respuesta, cuál es la pregunta? Tusquets, Barcelona.

Manuscrito A-1633 Aceito em 23 de março de 2007 